It is the bladder of a man which Mr. Liston had cut into above the pubes to relieve retention, thus allowing urine and a membrane to escape. The specimen exactly resembles the mucous membrane of a bladder separated as a slough in one piece.

Dr. J. J. Phillips relates another case* A young woman Shad a difficult labour, lasting, it is said, four days. Bladder distress followed, and a month after labour there was complete incontinence. The meatus urinarius was so dilated that it admitted the tip of the little finger. Next day there was expelled from the bladder a nearly complete cast. The patient recovered.

Dr. Schatz has related (Archiv für Gynäkologie) and figured another case of complete exfoliation by necrosis of the inner coat of the bladder consequent upon retention from retroversion of the gravid womb. The woman died, when the lining membrane of the bladder was found lying loose in the cavity of this organ. It is obvious that membrane so detached may fall into the urethra, and thus become a secondary cause of retention of urine.

The recognition of these cases is of great importance. One of Mr. Wells's cases, Dr. Wardell's, Dr. Phillps's, and one which I saw ended in recovery. Where obstruction to the voiding of urine is found from the pressure of some wubstance blocking the urethra from within, it would not be difficult to give relief by dilating the urethra, and drawing out the substance by forceps or a small blunt hook. Rest, demulcent drinks, and sedatives would diminish irritation whilst a new mucous membrane was forming.

The next effect of retention, and one which very quickly follows, is absorption of some of the fluid collected in the bladder. Then the retrograde pressure upon the ureters and kidneys leads to distension of these parts, and a diffculty of secretion. Congestion of the kidneys easily merges into nephritis; some degree of albuminuria is not uncommon; and the elements which ought to be excreted by the kidney being thrown back into the blood, the circulation is poisoned, and brain symptoms arise. It would be out of place here to discuss the theories that have been kroached as to the particular noxious element which thus empoisons the blood. I prefer the term urincemia to uræmia, as more comprehensive, and as less definitely assumptive of a precise knowledge. Blood-poisoning in this way is the most dangerous consequence of retention. It is more frequently the cause of death than any other condition.

Chronic cystitis and nephritis is the next consequence of retention. After the retention is relieved, and the bladder has recovered some amount of power, the whole urinary tract is subject to chronic inflammation.

Peritonitis sometimes follows retention of urine. It will, of course, be sometimes difficult to assign this with certainty to the retention as the cause, where great disorder of other pelvic organs which led to the retention coexists. But in some cases there is reason to suspect that, under the enormous pressure exerted by the distension of the bladder, increased by the futile efforts of the organ to expel its contents, some degree of oozing or permeation of the urine may have taken place through the coats, and thus have produced irritation of the peritoneal investment.

Starting, then, with the proposition that retention of urine may be caused by compression of the urethra against the symphysis pubis, we may usefully pursue the subject by inquiring what are the various causes that may exert this injurious compression. It will assist our analysis if we attempt to classify these causes.

We may bring together into groups-

1. Conditions inherent in the uterus itself.

2. Conditions external to the uterus, but acting for the most part by äriving the uterus against the bladder. The situation of these is of course behind the uterus. Other conditions have their seat in front of the uterus. Others, again, have a lateral position.

3. Vaginal conditions.

4. Conditions depending upon labour or the puerperal state.

5. Conditions, mostly dependent upon nervous disturbances, which do not fall under any of the preceding heads.

We will now proceed to the more particular discussion of the causes of retention, beginning with the first group of cases.

* British Medical Journal, 1871.
ON THE

\section{HEREDITARY TRANSMISSION OF EFFECTS OF CERTAIN INJURIES TO THE NERVOUS SYSTEM.}

\section{BY C. E. BROWN-SẼQUARD, M.D., F.R.S., F.R.C.P.I.}

IN a communication I made, in 1870, at Liverpool, to the members of the British Association for the Advancement of Science, I mentioned having witnessed a number of facts showing that alterations of ears or limbs, and certain morbid conditions, had appeared through heredity from parents in which the same alterations or conditions had been brought on by certain injuries to the nervous system. The facts I have observed-some before, others since that meetingconcerning the hereditary transmission to many animals of morbid states caused in one or other of their parents by some injury to the nerrous system, can be summed up as follows:-

1st. Appearance of epilepsy in animals born of parents having been rendered epileptic by an injury to the spinal cord.*

2nd. Appearance of epilepsy also in animals born of parents having been rendered epileptic by the section of the sciatic nerve.

3rd. A change in the shape of the ear in animals born of parents in which such a change was the effect of a division of the cervical sympathetic nerve.

4th. Partial closure of the eyelids in animals born of parents in which that state of the eyelids had been caused either by the section of the cervical sympathetic nerve or the removal of the superior cervical ganglion.

5th. Exophthalmia in animals born of parents in which an injury to the restiform body had produced that protrusion of the eyeball. This interesting fact I have witnessed a good many times, and I have seen the transmission of the morbid state of the eye continue through four generations. In these animals, modified by heredity, the two eyes generally protruded, although in the parents usually only one showed exophthalmia, the lesion having been made in most cases only on one of the corpora restiformia.

6th. Hematoma and dry gangrene of the ears in animals born of parents in which these ear-alterations had been caused by an injury to the restiform body near the nib of the calamus.

7th. Absence of two toes out of the three of the hind leg, and sometimes of the three, in animals whose parents had eaten up their hind-leg toes which had become anæsthetic from a section of the sciatic nerve alone, or of that nerve and also of the crural. Sometimes, instead of complete absence of the toes, only a part of one or two or three was missing in the young, although in the parent not only the toes but the whole foot was absent (partly eaten off, partly destroyed by inflammation, ulceration, or gangrene).

8th. Appearance of various morbid states of the skin and hair of the neck and face in animals born of parents having had similar alterations in the same parts, as effects of an injury to the sciatic nerve.

This is the fact $I$ shall $d$ well upon in this short paper; but before $I$ do so I think it is essential to make some general remarks about the circumstances relating to the various facts above mentioned.

As regards the transmission of epilepsy, it is clear that we must look upon that affection when it appears in the offspring as due to heredity, because in the species of animals (guinea-pigs) in which these facts have been observed I have never seen epilepsy except in those having had certain injuries able to produce that nervous complaint, or in the young born of these injured and thereby epileptic animals. My watching over guinea-pigs has been on such a scale (at one time, before the siege of Paris, I had 584 in my laboratory) that I can say I have had many and many thousands under observation from 1843 till now-a period of more than thirty years.

Of the various kinds of hereditary transmission I have mentioned, only two are very frequent-exophthalmia and

* This fact I discovered long ago. (See the Proceedings of the Royal Society, Jane, 1860, vol. x., p. 297.) 
the change in shape of the ear. The absence of toes is rare. Since I have paid attention to it as an instance of hereditary transmission $I$ bave only recorded it thirteen times, althongh $I$ know that $I$ have seen it in more than thirteen animals. I have come to the conclusion that this condition of the foot deprived of toes is due to heredity from this reason, that I have never seen a guinea-pig born toeless which was not the offspring of parents accidentally deprived of toes. Besides, the congenital absence of toes has never existed but in the hind legs, limbs which were also the only toeless ones in the parents. I should say, however, that in two animals both bind legs were partly toeless, while the father in one case, and the mother in the other, had toes missing only in one of the hind legs. A similar observation I have made, and already mentioned, as regards the protrusion of the eyeballs; a number of animals had both eyes protruding, although their parents had exophthalmia only on one side.

In most of the instances of heredity that I have observed only one of the parents had been operated upon, and had the alteration which was transmitted.

I now come to the fact to which I wish especially to call attention. I have made the following observations only in two animals, but in both of them all the features $I$ will mention were perfectly manifest.

$I$ have already stated that the young of guinea-pigs born of parents having had a section of the sciatic nerve sometimes become epileptic. This inherited epilepsy I have never observed in other animals than those which had also inherited an absence of toes. Now, as regards these toeless animals, I have been able in two of them, as already stated, to follow up the changes I will mention.

It is pretty well known that $I$ have found that some time after the section of the sciatic nerve in guinea-pigs the sensibility of the skin of some parts of the face and neck on the side of the operation becomes very different from what it was; it diminishes as regards its power of giving rise to pain under a prick, a pinch, or a galvanio current, at the same time that appears in that skin the power, when tickled or gently pinched, to produce some convulsive reflex movement. At first there is only a reflex spasm of some muscles of the face and neck; gradually the number of muscles contracting and the energy of the spasm increase, and after a few days the whole side of the body on which the nerve has been divided contracts powerfully. A little later the muscles of the other side become also convulsed, and the head is shaken to and fro from side to side. A few days later the attack becomes more complete. Not only the convulsions are more easily produced and become more violent, but also there is sometimes loss of consciousness and a state of torpor stupidity, and even in a few instances of insanity, for a while after the attack. In the meanwhile the divided ends of the sciatic nerve begin to unite, and when reunion progresses, three very remarkable facts can be witnessed. The skin of the face and neck recover gradually their sensibility to mechanical or galvanic irritation, the fits gradually diminish in intensity, the changes for the better occurring just by opposite steps to those followed while the trouble was increasing, and we find also that the hair gradually falls off from the cutaneous zone, the excitation of which by tickling or gentle pinching was able to give rise to an epileptic attack. The beginning of this fall of hair marks the turning-point of the nervous affection. As soon as it appears, a decrease of violence of the convulsive complaint begins to be noticed.

Now all these peculiarities-the gradual increase of the affection, the diminution of sensibility in the epileptogenous zone, the coming of a period of complete attacks of epilepsy, and then the loss of hair, and the gradual diminution of the nervous complaint-all these things in all their details I have witnessed also in two guinea-pigs born toeless by heredity, and having also by heredity become epileptic.

There is therefore an inheritance not only of an aptitude of being seized with convulsions, but of the whole nervous affection of the father or mother in all its features, from beginning to end, and in the same order. This certainly is quite remarkable, but what is still more so is that in the parent there are changes which we know to occur in the sciatic nerve, which we find to be connected with the different stages of the convulsive affection, and especially there is the co-existence of the reunion of the divided nerve and of the amelioration at the time of the fall of hair; while in the toeless-born animals there is no division of the sciatic nerve to give rise to the trouble, and still less a reunion of separated ends of nerve to explain the amelioration. We must conclude therefore that the sciatic nerve in the congenitally toeless animal has inherited the power of passing through all the different morbid states which have occurred in one of its parents in the central end of the sciatic nerve from the time of the division till after its reunion with the peripheric end. It is not therefore simply the power of performing an action which is inherited, but the power of performing the whole of a series of actions, and in a certain order.

In almost all, if not in all, the cases of hereditary transmission $I$ have observed in animals in whose parents $I$ had injured either the sciatic nerve, the cervical sympathetic nerve, or the corpus restiformis, most likely what is transmitted is the morbid state of the nervous system. There is possibly an exception in the fact that some animals were born toeless from their parents having lost their toes; but the other facts only imply the transmission of a morbid state of the sympathetic or sciatic nerve or of a part of the medulla oblongata.

These facts, added to many others mentioned by P. Lucas and by Charles Darwin, $\uparrow$ clearly prove the possibility of here. ditary transmission of effects of mere accidental injuries.

\section{ON CERTAIN POINTS RELATING TO THE ETIOLOGY, PATHOLOGY, AND TREAT- MENT OF DIPHTHERIA.\$}

BY GEORGE JOHNSON, M.D., F.R.S., PROFESSOR OF MIEDICTNE IN KING'S COLLEGR, SFMYR PHYSYCIAY TO KING'S COLLEGE HOSPITAX.

I PROPOSE in the present communication to discuss some important practical questions relating to the etiology, the pathology, and the treatment of diphtheria.

There are some practitioners who, believing that diphtheria is a specific contagious disease, maintain that defective drainage and filth bave little or no influence in its causation, while others, denying its contagiousness, assert that its origin and spread may always be explained by insanitary conditions. I believe that both classes of negationists are in error. I have no doubt that the disease, though not highly contagious, is communicable from the sick to the healthy, and I have as little doubt that it is often caused by filthy emanations from sewers and cesspools, and this. too, when it is in the highest degree improbable that any specific poison can have been introduced from without into the decomposing stuff that has excited the disease. In: proof of the contagiousness of diphtheria, the following. amongst a multitude of similar cases, may be set forth.

M. Valleix, a colleague of Trousseau, while examining the throat of a patient, received into his mouth a small quantity of saliva spurted out by the patient in coughing. Next day g. $^{\circ}$ on one of his tonsils there was a pellicular deposit, and some hours later both tonsils and the uvula were covered by false membrane; the disease made rapid progress, and in forty-eight hours he died. Another of Trousseau's provincial colleagues was performing tracheotomy in a case of diphtheritic croup, when he applied his mouth to the wound to suck blood from the trachea. He thus inoculated himself, and died in forty-eight hours. $\S$

Sir William Jenner states that Dr. E- - lived in Euston. road. He was attending a child ill from diphtheria, when he sickened with the same disease. As he recovered his attendant was attacked with it. No one in his house suffered except Dr. E- and the young woman who was in constant attendance upon him. The child from whom

* Traité Philosoph. et Physiol. de i'Hérédité Naturelle. Paris, 1850。 Two vols. 8vo.

$\frac{t}{\dagger}$ The Variation of Animals and Plants under Domestication. London, 1 The Variation of
1868. Two vols. 8vo.

t Read before the West Kent Mredico.Chirurgical Society, Dec. 4th, 187 $\S$ Trousseau's Clinical Medicine, New Sydenham Society, vol. ii., p. 493. 